\title{
Results of mini open latarjet procedure for recurrent shoulder dislocation in Indian population:A Series Of 30 Cases.
}

\author{
Dr. S. Sasibhushana Rao ${ }^{1}$, Dr. S. David Raju ${ }^{2}$, Dr. V. Chiranjeevi ${ }^{3}$. \\ 1. Associate Professor Of Orthopaedics Department,Department Of Orthopaedics, MIMS Medical College And \\ Hospital, Nellimarla, Vizianagaram, Andhra Pradesh, India. \\ 2. Professor and HOD Of Orthopaedics Department,Department Of Orthopaedics, MIMS Medical College And \\ Hospital, Nellimarla, Vizianagaram, Andhra Pradesh, India. \\ 3. Senior Resident,Department Of Orthopaedics, MIMS Medical College And Hospital, Nellimarla, \\ vizianagaram,Andhra Pradesh, India
}

\begin{abstract}
More than 200 different operations have been described for the treatment of recurrent anterior dislocation of shoulder. The Latarjet procedure employs rerouting of the osteotomised coracoid process with its attached conjoined tendon through a split in the substance of subscapularis and fixed to the antero inferior aspect of glenoid rim. Since 2011 Latarjet procedure was performed on 30 patients, who presented with recurrent dislocation of shoulder (28 men and 2 women). Patients were evaluated using ROWE instability score, Oxford Shoulder Instability index Score at the last follow up. There was no single episode of recurrence of dislocation or subluxation, all the patients regained preoperative range of motion. Mean ROWE score is 90 (excellent) \& mean oxford shoulder instability index is 38 (good). Latarjet procedure is an excellent surgical option for recurrent shoulder instability associated with glenoid bone deficiency with or without engaging hillsachs lesion.
\end{abstract}

Keywords: Recurrent shoulder dislocation, Latarjet procedure, Corocoid process, ROWE Score, Oxford Shoulder Instability Score.

\section{Introduction}

The use of the coracoid process to stabilise the shoulder was first described by Oudard ${ }^{1}$ in 1923 . He introduced a bone graft into a split in the horizontal part of the coracoid apophysis to fill the coracoglenoidal space. Screwing of the coracoid process on to the anteroinferior side of the glenoid at the level of the anterior glenoid rim was described by Latarjet ${ }^{2}$ in 1954. In his original technique, subscapularis was incised vertically along the whole of its length, then sutured with an over- lap. In 1958, Helfet ${ }^{3}$ described suturing the tip of the coracoid process to the preglenoidal fibrous plane by splitting subscapularis. The aim was to create a hammock to stabilise the shoulder in maximal abduction and external rotation. Patte et al ${ }^{4}$ proposed changes in 1980 to Latarjet's technique by developing the concept of anterior triple locking, which involved a bone-block effect, suturing of the coraco- acromial ligament to the medial capsular flap with preservation of the lower third of the ten- don of subscapularis.

Our aim was to study the functional outcome of latarjet procedure in Indian population as many of these patients present with recurrent episodes of dislocation and most of these patients have glenoid bone loss with or without an assosciated hillsachs lesion. We also tried to compare our results with previously published studies in the literature.

\section{Materials And Methods}

All patients who have presented to our orthopaedics department between November 2011 to January 2014 with recurrent episodes of anterior shoulder dislocation were evaluated clinically and radiologically (antero-posterior view, trans-axillary lateral view, scapular y view, CT Scan and MRI Scan). A total of 30 patients (28 male and 2 female) with mean age at the time of surgery was 22.2 years (18-30 years) with recurrent episodes of anterior shoulder dislocation and glenoid bone loss $(>25 \%)$ with or without an engaging hillsachs lesion were included in our study. Patients with an isolated bankarts leison, hyperlaxity on examination, surgically unfit, were excluded.

Patient is placed in beach chair position and shoulder was approached using delto pectoral interval. Corocoid process with its attached conjoint tendon identified and corocoid was osteotomised at its angle. Subscapularis muscle is split horizontally at the junction of upper two thirds and lower one third near the musculo-tendinous junction and the capsule was incised vertically. Osteotomised corocoid was placed over the glenoid defect and fixed with two $4 \mathrm{~mm}$ cannulated cancellous screws and wound closed in layer. Shoulder was immobilised in arm pouch for a period of one week and post operative physiotherapy was started after one week. Mean follow up period was 1 year ( 6 months to 2 years). Post operative shoulder function was evaluated 
using ROWE Score and Oxford Shoulder Instability Index. We compared our results with previous published literature.
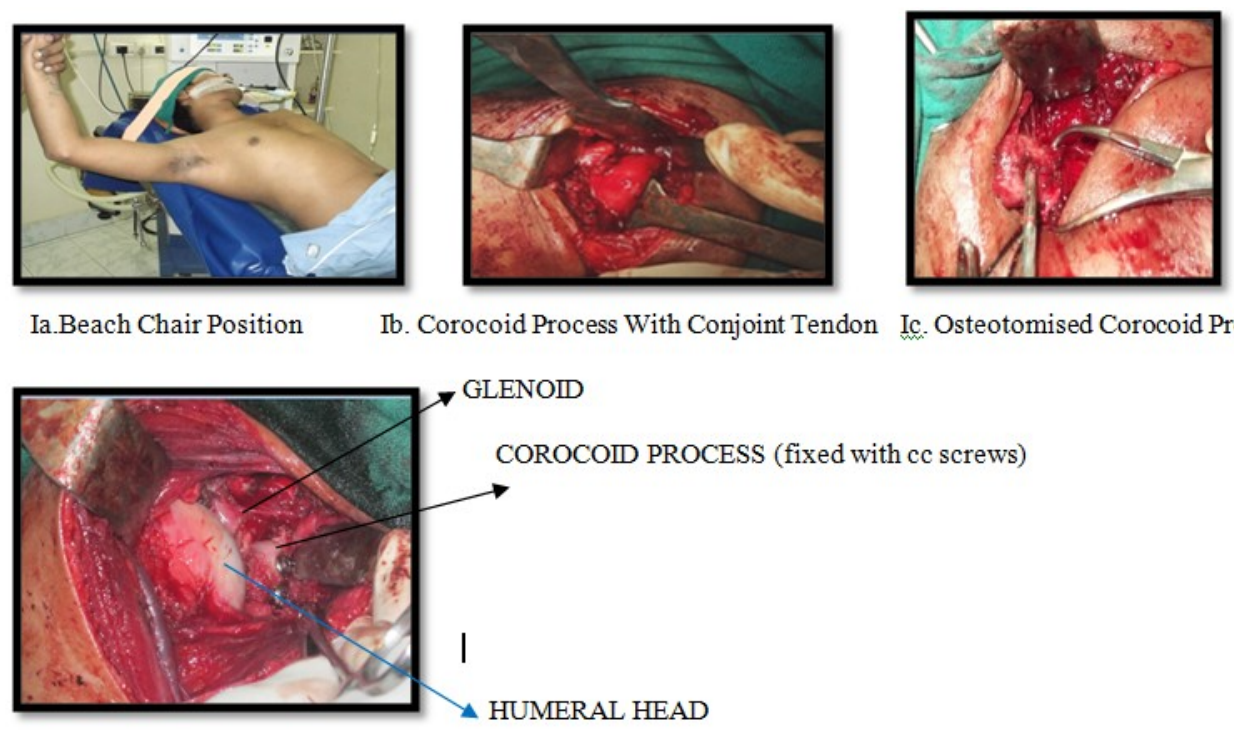

Id. Corocoid process fixed with cc screws

\section{Results}

All patients were followed for a period of average 1 year (6 months to 2 years), during this period no patient had recurrence of shoulder dislocation. Post operative range of motion of shoulder was almost fully achieved. Mean abduction was $170 \mathrm{deg}$ (150-180 deg), mean external rotation loss was $20 \mathrm{deg}$ (15-25 deg). All patients had a positive apprehension test pre operatively and all these patients found to have a negative apprehension test post operatively. Mean OSII score was 38.4(28-44), mean ROWE score was 90 (70-100). 29 of the 30 patients had excellent to good results and 1 patient had fair result based on ROWE and OSII score. At the latest follow up all the post operative radiographs had shown good union of corocoid process and none had osteoarthritic changes.

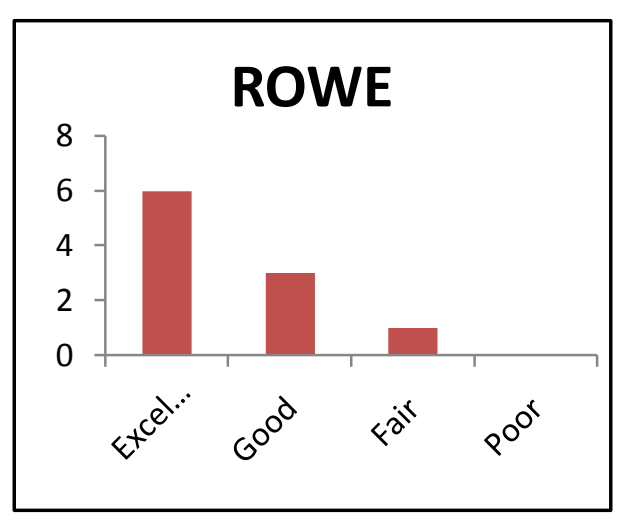

Fig II

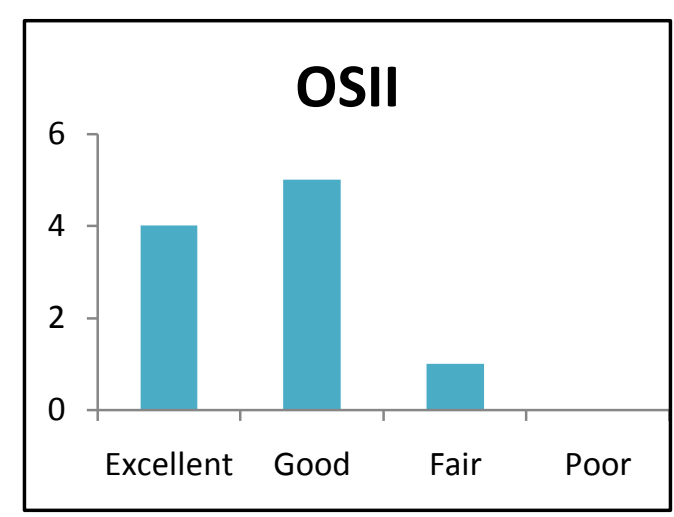

Fig III (case I)
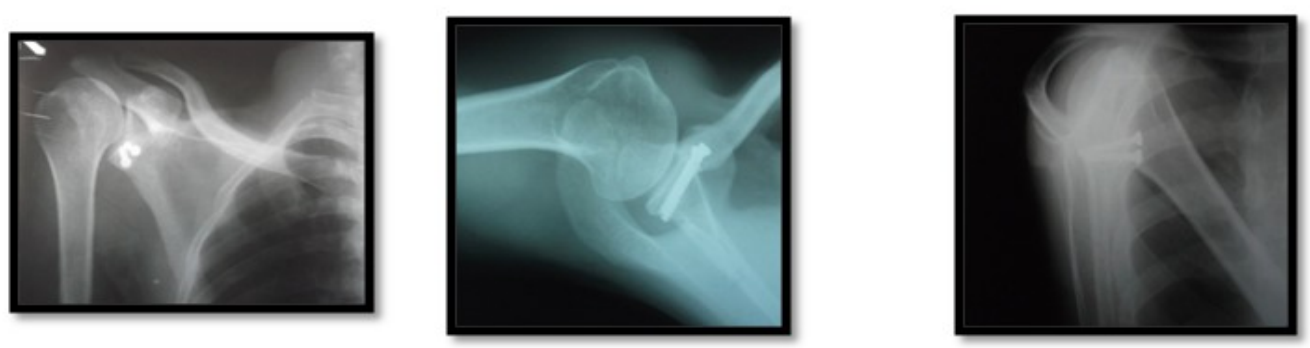

IIIa. Post oprative radiographs 

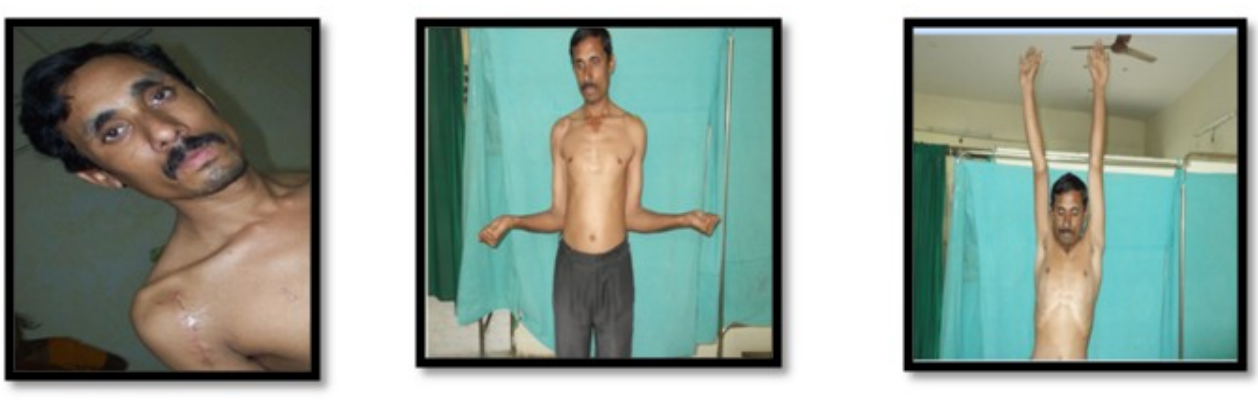

IIIb. Post operative range of motion

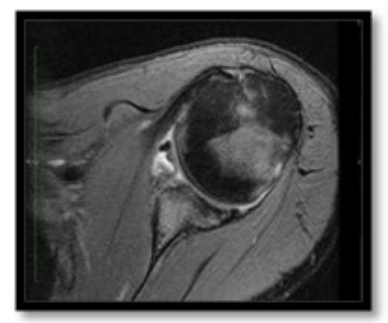

IVa. Pre Op MRI

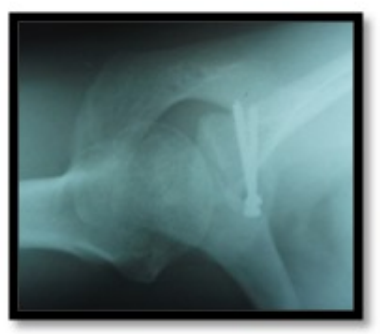

IVd. Post Op Radiographs

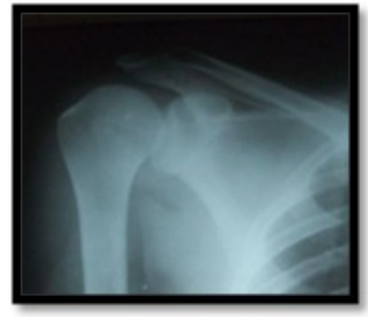

IVb.Pre Op Radiograph

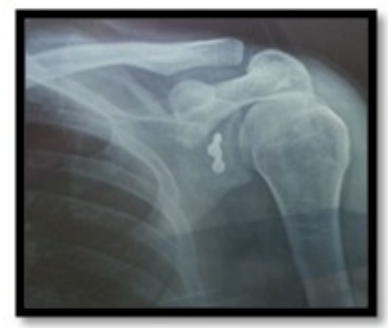

IV. Discussion

Most commonly performed surgery for shoulder dislocation is an open or an arthroscopic bankarts repair as the commonly assosciated lesion is an bankarts lesion. This surgery gives excellent results if done for an isolated bankarts lesion, but poor results are reported if glenoid bone loss was the major contributing factor for recurrent dislocation of shoulder. Studies by balg \& boileau ${ }^{7}$, Uhorchak and colleagues, Burkhart and De Beer $^{8}$ proved high recurrence rate with arthroscopic bankarts repair done for recurrent shoulder instability associated with significant bone defects of glenoid.

The Latarjet procedure is a useful form of treatment for patients with recurrent anterior dislocation of the shoulder., ${ }^{9,10}$ The mechanisms by which this technique achieves stability include the following three effects: 1) the creation of a sling mechanism by the conjoint tendon crossing the lower part of the subscapularis muscle, compressing this and the anteroinferior capsule against the humeral head; 2) the restoration of the anterior glenoid rim by the transposed coracoid process; and 3) repair of the capsule, which is performed using the stump of the resected coraco-acromial ligament. Excellent long-term results, with low rates of redislocation, have been described. ${ }^{11,12}$

There were many studies published in the literature regarding latarjet procedure most of them are on foreign nationalists, none of them were on Indian population. We studied the results of latarjet procedure on Indian population and compared it with previously published literature. 


\begin{tabular}{|c|c|c|c|c|c|c|}
\hline STUDIES & $\begin{array}{c}\text { NO OF } \\
\text { PATIENTS }\end{array}$ & $\begin{array}{c}\text { SUBLUXAT-ION } \\
\text { RATE }\end{array}$ & $\begin{array}{c}\text { ROWE } \\
\text { EXCELLENT }\end{array}$ & $\begin{array}{c}\text { ROWE } \\
\text { GOOD }\end{array}$ & $\begin{array}{c}\text { ROWE } \\
\text { FAIR }\end{array}$ & $\begin{array}{c}\text { ROWE } \\
\text { POOR }\end{array}$ \\
\hline Banas et al., 1993 & 79 & $4 \%$ & $74 \%$ & $11 \%$ & $9 \%$ & $6 \%$ \\
\hline Singer et al.,1995 & 14 & $0 \%$ & $36 \%$ & $57 \%$ & $7 \%$ & $1 \%$ \\
\hline Pap et al., 1997 & 31 & $3 \%$ & $45 \%$ & $39 \%$ & $6 \%$ & $10 \%$ \\
\hline Hovelius et al2004 & 118 & $4 \%$ & $71 \%$ & $15 \%$ & $11 \%$ & $4 \%$ \\
\hline Matthes et al 2007 & 29 & $0 \%$ & $59 \%$ & $24 \%$ & $10 \%$ & $7 \%$ \\
\hline Present study 2013 & 10 & $0 \%$ & $60 \%$ & $30 \%$ & $10 \%$ & - \\
\hline
\end{tabular}

\section{Conclusion}

In our study of 30 cases 29 patients had excellent to good results based on ROWE score and OSII score. Post operative range of motion of shoulder was almost fully achievedin all patients. Mean abduction was $170 \mathrm{deg}$ (150-180 deg), mean external rotation loss was $20 \mathrm{deg}$ (15-25 deg). None of our patients had recurrent episode of dislocation posteratively till the latest followup. Soft tissue Bankart repairs yield good results when used for capsulolabral avulsions and tears.Patients with more complex leisons need a surgical option that addresses these lesions. With good clinical and radiological evaluation more complex lesions like bony bankarts and bankarts with associated hillsachs leison can be identified and successfully treated by latarjet procedure.

\section{References}

[1]. Oudard M. La luxation récidivante de l'épaule, procédé opératoire. J Chir 1923;23: 13-25 (in French).

[2]. Latarjet M. Treatment of recurrent dislocation of the shoulder. Lyon Chir 1954;49: 994-1003.

[3]. Helfet AJ. Coracoid transplantation for recurring dislocation of the shoulder. J Bone Joint Surg [Br] 1958;40-B:198-202.

[4]. Patte D, Bernageau J, Rodineau J, et al. Unstable painful shoulders. Rev Chir Orthop Reparatrice Appar Mot 1980;66:157-65 (in French).

[5]. Torg JS, Balduini FC, Bonci C, et al. A modified Bristow-Helfet-May procedure for recurrent dislocation and subluxation of the shoulder: report of two hundred and twelve cases. Latarjet M. A propos du traitement des luxations re' cidivantes de l'e'paule. Lyon Chir 1954;49:994-1003.

[6]. Boileau P, Villalba M, Hery JY, et al. Risk factors for recurrence of shoulder instability after arthroscopic Bankart repair. J Bone Joint Surg Am 2006;88(8):1755.

[7]. Balg F, Boileau P. The instability severity index score. A simple pre-operative score to select patients for arthroscopic or open shoulder stabilisation. J Bone Joint Surg Br 2007;89(11):1470-7.

[8]. Burkhart SS, De Beer JF. Traumatic glenohumeral bone defects and their relationship to failure of arthroscopic Bankart repairs: significance of the inverted-pear glenoid and the humeral engaging Hill-Sachs lesion. Arthroscopy 2000;16(7):677-94.

[9]. Patte D, Debeyre J. Luxations recidivantes del'epaule. Paris-Technique chirurgicale. Orthopedie. Encycl Med Chir 1980;44265:4452.

[10]. Itoi E, Lee SB, Berglund LJ, et al. The effect of a glenoid defect on anteroinferior stability of the shoulder after Bankart repair: a cadaveric study. J Bone Joint Surg Am 2000;82(1):35-46.

[11]. Piasecki DP, Verma NN, Romeo AA, et al. Glenoid bone deficiency in recurrent anterior shoulder instability: diagnosis and management. J Am Acad Orthop Surg 2009;17(8):482-93.

[12]. Burkhart SS, De Beer JF, Barth JR, et al. Results of modified Latarjet reconstruction in patients with anteroinferior instabi lity and significant bone loss. Arthroscopy 2007;23(10):1033-41. 